\title{
Nanosomal Docetaxel Lipid Suspension-Based Chemotherapy in Breast Cancer: Results from a Multicenter Retrospective Study
}

This article was published in the following Dove Press journal: Breast Cancer: Targets and Therapy

\author{
Sundaram Subramanian' \\ Rammohan Prasanna (D) ${ }^{2}$ \\ Ghanashyam Biswas ${ }^{3}$ \\ Saroj Kumar Das Majumdar ${ }^{4}$ \\ Nisarg Joshi ${ }^{5}$ \\ Deepak Bunger ${ }^{5}$ \\ Mujtaba A Khan (1D ${ }^{5}$ \\ Imran Ahmad (D) ${ }^{6}$ \\ 'VS Hospital, Madras Cancer Institute, \\ Advanced Cancer Care, Chennai, Tamil \\ Nadu 60003I, India; ${ }^{2}$ Department of \\ Medical Oncology, CBCC-GVN Cancer \\ Center, Tiruchirappalli, Tamil Nadu \\ 620005, India; ${ }^{3}$ Department of Medical \\ Oncology, Sparsh Hospital, Bhubaneswar, \\ Odisha 751007, India; ${ }^{4}$ Department of \\ Radiotherapy, All India Institute of \\ Medical Sciences, Bhubaneswar, Odisha \\ 751019 , India; ${ }^{5}$ Medical Affairs and \\ Clinical Development, Intas \\ Pharmaceuticals Ltd., Ahmedabad, \\ Gujarat 380054, India; ${ }^{6}$ Jina \\ Pharmaceuticals Inc., Libertyville, \\ Illinois, USA
}

Correspondence: Imran Ahmad jina Pharmaceuticals Inc., Libertyville, IL, USA

Email imran@jinapharma.com
Purpose: The purpose of this study was to evaluate the efficacy and safety of nanosomal docetaxel lipid suspension (NDLS, DoceAqualip)-based chemotherapy in breast cancer.

Methods: Medical charts of patients with breast cancer, who were treated and followed up with NDLS (75-100 mg/m²; 3-week cycle)-based chemotherapy from August 2014 to September 2018, were analyzed in this multicenter, retrospective study. The study endpoints were overall response rate (ORR: complete response $[\mathrm{CR}]+$ partial response $[\mathrm{PR}]$ ) and disease control rate (DCR: $\mathrm{CR}+\mathrm{PR}+$ stable disease [SD]) in neoadjuvant and metastatic settings. Overall survival (OS) and safety were evaluated for all settings.

Results: Of 91 patients (neoadjuvant: 12, adjuvant: 61, metastatic: 18), efficacy evaluation in 29 patients (neoadjuvant: 12/12, metastatic: 17/18) demonstrated an ORR and DCR of $100 \%$, respectively, in the neoadjuvant setting, and an ORR of $64.7 \%$ and DCR of $70.6 \%$, respectively, in the metastatic setting. At a median follow-up of 21.6 months (range: 2.1 to 49.9 months), median OS was not reached in neoadjuvant and adjuvant settings, and it was 30.4 months in metastatic settings. At least one adverse event (AE) was reported in $59.3 \%$ of patients. Anemia, thrombocytopenia, lymphopenia, and neutropenia were the most common hematological AEs reported while hyperglycemia and alteration in liver function tests were the most common non-hematological AEs. NDLS-based treatment was well tolerated without any new safety concerns.

Conclusion: Nanosomal docetaxel lipid suspension-based chemotherapy was efficacious and well tolerated in the treatment of breast cancer. Further, NDLS is being evaluated prospectively in patients with triple-negative breast cancer (ClinicalTrials.gov: NCT03671044).

Keywords: DoceAqualip, NDLS, nanosomal docetaxel lipid suspension, breast cancer

\section{Introduction}

Breast cancer is one of the most common cancers globally. ${ }^{1}$ In women, breast cancer is the most commonly diagnosed cancer and a leading cause of cancer mortality worldwide. ${ }^{2}$ As per the GLOBOCAN 2018 report, breast cancer accounts for $11.6 \%$ of all cancer cases with 2,088,849 new cases and $626,679(6.6 \%)$ deaths reported globally. In India, breast cancer has an incidence of $27.7 \%(n=162,468)$ among all cancers in women. ${ }^{2,3}$

Docetaxel has emerged as the agent of choice with established efficacy and tolerability in the treatment of breast cancer. ${ }^{4}$ Docetaxel is approved for the treatment of locally advanced or metastatic breast cancer (MBC) and for adjuvant 
treatment of operable node-positive breast cancer. $^{5}$ Docetaxel has also demonstrated efficacy and tolerability in the neoadjuvant treatment of operable breast cancer. ${ }^{6,7}$

The conventional formulation of docetaxel has several toxicity issues related to its excipients, polysorbate 80 and ethanol, such as acute hypersensitivity reactions, ${ }^{8,9}$ cumulative fluid retention, ${ }^{10}$ peripheral neuropathy, ${ }^{11}$ severe anaphylactoid reactions, ${ }^{12}$ infusion-site reactions, ${ }^{13}$ and alcohol intoxication. ${ }^{14,15}$ Corticosteroids and antihistamines are used as premedication to overcome these toxicities, ${ }^{16-18}$ but these adverse effects may still occur in some patients. ${ }^{19}$ A novel lipid based, polysorbate 80 and ethanol free formulation of docetaxel, nanosomal docetaxel lipid suspension (NDLS, DoceAqualip, of Intas Pharmaceuticals Limited, India), was developed to overcome these toxicity issues. ${ }^{20}$ NDLS has shown comparable efficacy and tolerability to conventional docetaxel in the treatment of $\mathrm{MBC}$ in a prospective study. ${ }^{20}$ NDLS has also demonstrated efficacy and safety for the management of breast cancer in previous retrospective studies. ${ }^{21,22}$ The current report presents a multicenter, retrospective experience in real-world practice evaluating the efficacy and safety of NDLS-based chemotherapy in the treatment of breast cancer.

\section{Methods}

\section{Study Design}

In our multicenter, observational, retrospective study, medical charts of women with breast cancer, who were treated with NDLS-based chemotherapy as part of their routine clinical care at four centers across India, were analyzed. The study endpoints were overall response rate (ORR: proportion of patients achieving complete [CR] +partial response $[\mathrm{PR}]$ ), disease control rate (DCR: CR $+\mathrm{PR}+$ stable disease [SD]) and overall survival (OS, defined as time from treatment to death due to any cause; for patients who were still alive at the time of data analysis or who were lost to follow-up, OS was censored at the last recorded date that the patient was known to be alive). ORR and DCR were analyzed for patients who received NDLS-based treatment in neoadjuvant and metastatic settings, and OS was evaluated for all patients. Treatment response was evaluated using Response Evaluation Criteria in Solid Tumors (RECIST) $1.1 .^{23}$ Incidence of adverse events (AEs) documented in the treatment charts were recorded and graded according to the National Cancer Institute Common Terminology
Criteria for Adverse Events (CTCAE) Criteria version 5. ${ }^{24}$ Similarly, data on death and discontinuations were captured from patients' health records.

\section{Ethics Statement}

The study protocol was reviewed and approved by OM ethics committee, Ahmedabad, India. The study was conducted in accordance with the ethical principles that have their origin in the Declaration of Helsinki, and in accordance with the International Conference on Harmonization's Good Clinical Practice guidelines, applicable regulatory requirements, and in compliance with the protocol. Patient consent to review their medical records was not required by the committee as NDLS is already approved in India and patient confidentiality was completely maintained. In this retrospective study, no patient identifiers were used and data were anonymized.

\section{Statistical Analyses}

Demographic and baseline characteristics were summarized using descriptive statistics. Categorical variables were summarized with frequency and percentage. Continuous variables were summarized with count, mean, standard deviation, median, minimum, and maximum. Response rate was evaluated as per RECIST 1.1 and presented as frequency and percentage of patients. Survival analysis was performed to measure lifetime or the length of time until the occurrence of an event (death in case of overall survival). Survival data was analyzed using a nonparametric procedure performed on PROC LIFETEST of SAS (Version 9.4) to measure the duration of time until a specified event occurs. OS was calculated and analyzed using Kaplan-Meier method and Log rank test to estimate the survival function from lifetime data after treatment. The AEs were summarized as frequencies and percentages by type of reactions.

\section{Results}

\section{Patients Disposition and Demographics}

Data of 91 women with breast cancer, who were treated with NDLS-based chemotherapy, were analyzed. The baseline characteristics of these patients are summarized in Table 1.

NDLS was used as a 1-hour infusion in 3-week cycles at a dose of $75 \mathrm{mg} / \mathrm{m}^{2}(93.4 \%, 85 / 91)$ or $100 \mathrm{mg} / \mathrm{m}^{2}$ $(6.6 \%, 6 / 91)$. NDLS-based regimens were used as firstline therapy in the majority $(88.5 \%)$ of the patients. Most $(n=60,98.4 \%)$ of the patients were administered premedications; dexamethasone was the most common agent. 
Table I Patient Disposition and Baseline Characteristics

\begin{tabular}{|c|c|c|c|c|}
\hline Parameters & $\begin{array}{l}\text { All patients } \\
(\mathrm{N}=91)\end{array}$ & $\begin{array}{l}\text { Neoadjuvant Setting } \\
(\mathrm{N}=12)\end{array}$ & $\begin{array}{l}\text { Adjuvant Setting } \\
(\mathrm{N}=6 \mathrm{I})\end{array}$ & $\begin{array}{l}\text { Metastatic Setting } \\
(\mathrm{N}=18)\end{array}$ \\
\hline $\begin{array}{l}\text { Age (years), mean } \pm S D \text {, } \\
\text { range } \\
B S A, k g / \mathrm{m}^{2}, \text { mean } \pm S D\end{array}$ & $\begin{array}{l}51.3 \pm 11.2(26-76) \\
1.60 \pm 0.2\end{array}$ & $\begin{array}{l}51.3 \pm 13.3(31-76) \\
1.71 \pm 0.1\end{array}$ & $\begin{array}{l}49.1 \pm 10.8(26-74) \\
1.59 \pm 0.2\end{array}$ & $\begin{array}{l}58.9 \pm 7.8(4 I-75) \\
1.60 \pm 0.2\end{array}$ \\
\hline $\begin{array}{l}\text { Women, n (\%) } \\
\text { Premenopausal } \\
\text { Post-menopausal }\end{array}$ & $\begin{array}{l}29(31.9) \\
62(68.1)\end{array}$ & $\begin{array}{l}4(33.3) \\
8(66.7)\end{array}$ & $\begin{array}{l}24(39.3) \\
37(60.7)\end{array}$ & $\begin{array}{l}\text { I (5) } \\
\text { I7 (94.4) }\end{array}$ \\
\hline $\begin{array}{l}\text { Cancer Stage, n (\%) } \\
\text { I } \\
\text { II } \\
\text { III } \\
\text { IV }\end{array}$ & $\begin{array}{l}3(3.3) \\
31(34.1) \\
39(42.9) \\
18(19.8)\end{array}$ & $\begin{array}{l}\text { I (8.3) } \\
2(16.7) \\
9(75.0) \\
-\end{array}$ & $\begin{array}{l}2(3.3) \\
29(47.4) \\
30(49.3) \\
-\end{array}$ & $\begin{array}{l}- \\
- \\
- \\
18(100)\end{array}$ \\
\hline $\begin{array}{l}\text { Metastasis Site, } \mathrm{n}(\%)^{\mathrm{a}} \\
\text { Lymph node } \\
\text { Bone } \\
\text { Brain } \\
\text { Liver } \\
\text { Lung }\end{array}$ & $\begin{array}{l}4(4.4) \\
4(4.4) \\
I(1.1) \\
I(1.1) \\
4(4.4)\end{array}$ & $\begin{array}{l}- \\
- \\
- \\
-\end{array}$ & $\begin{array}{l}4(6.6) \\
- \\
- \\
- \\
-\end{array}$ & $\begin{array}{l}- \\
4(22.2) \\
\text { I }(5.6) \\
\text { I }(5.6) \\
4(22.2)\end{array}$ \\
\hline $\begin{array}{l}\text { Hormonal Receptor Status } \\
\text { ER+/PR+ } \\
\text { HER2+ } \\
\text { TNBC }\end{array}$ & $\begin{array}{l}43(47.3) \\
38(4 I .8) \\
25(27.5)\end{array}$ & $\begin{array}{l}8(66.7) \\
5(41.7) \\
2(16.7)\end{array}$ & $\begin{array}{l}24(39.3) \\
24(39.3) \\
18(29.5)\end{array}$ & $\begin{array}{l}\text { II (6I.I) } \\
9(50) \\
5(27.8)\end{array}$ \\
\hline $\begin{array}{l}\text { ECOG Score, } n(\%)^{c} \\
0 \\
1 \\
2 \\
3\end{array}$ & $\begin{array}{l}4(4.4) \\
50(54.9) \\
34(37.4) \\
1(1.1)\end{array}$ & $\begin{array}{l}6(50) \\
6(50) \\
-\end{array}$ & $\begin{array}{l}2(3.3) \\
36(59) \\
21(34.4) \\
I(1.6)\end{array}$ & $\begin{array}{l}2(11.1) \\
8(44.4) \\
7(38.9) \\
-\end{array}$ \\
\hline $\begin{array}{l}\text { Comorbid Disease, n (\%) } \\
\text { Hypertension } \\
\text { Diabetes }\end{array}$ & $\begin{array}{l}10(11) \\
19(20.9)\end{array}$ & $\begin{array}{l}2(16.7) \\
3(25)\end{array}$ & $\begin{array}{l}6(9.8) \\
10(16.4)\end{array}$ & $\begin{array}{l}2(11.1) \\
6(33.3)\end{array}$ \\
\hline
\end{tabular}

Notes: ${ }^{a}$ Metastasis sites were not available for four patients. ${ }^{b}$ Number of patients in ER+/PR+ and HER2+ may overlap. ${ }^{c} E C O G$ score not available for two patients in adjuvant setting. Other comorbid diseases included hypothyroidism, arthritis, coronary artery disease, dyslipidemia, and ischemic heart disease.

Abbreviations: BSA, body surface area; ER, estrogen receptor, HER2, human epidermal growth factor receptor 2; PR, progesterone receptor, SD, standard deviation; TNBC, triple-negative breast cancer.

Granulocyte-colony stimulating factor (GCSF) was used in the majority of the patients $(97.8 \%, 90 / 91)$ as primary prophylaxis.

\section{NDLS-Based Treatment Regimens}

The most common NDLS-based treatment regimens were: neoadjuvant setting, NDLS plus carboplatin plus trastuzumab (TCH, 33.3\%, 4/12) and 5-FU plus epirubicin plus cyclophosphamide followed by NDLS (FEC $\rightarrow$ T, 25\%, 3/ 12); adjuvant setting, NDLS plus cyclophosphamide (TC, $23 \%, 14 / 61$ ), TCH and NDLS plus doxorubicin plus cyclophosphamide (TAC) $(21.3 \%$ each, 13/61), and metastatic setting: NDLS plus carboplatin $(44.4 \%, 8 / 18)$ and $\mathrm{TCH}$ $(33.3 \%, 6 / 18)$.

\section{Efficacy}

Of 30 patients who received NDLS for the treatment of breast cancer in metastatic and neoadjuvant settings, efficacy evaluation was available for 29 patients (12/12 in neoadjuvant and $17 / 18$ in metastatic settings). Patients who received NDLS in the adjuvant setting $(n=61)$ were considered for safety and OS analysis. In the neoadjuvant setting, both ORR and DCR were 100\% (CR: 50\% [6/12], PR: 50\% [6/12]), respectively (Figure 1A), whereas in the metastatic setting, ORR was 

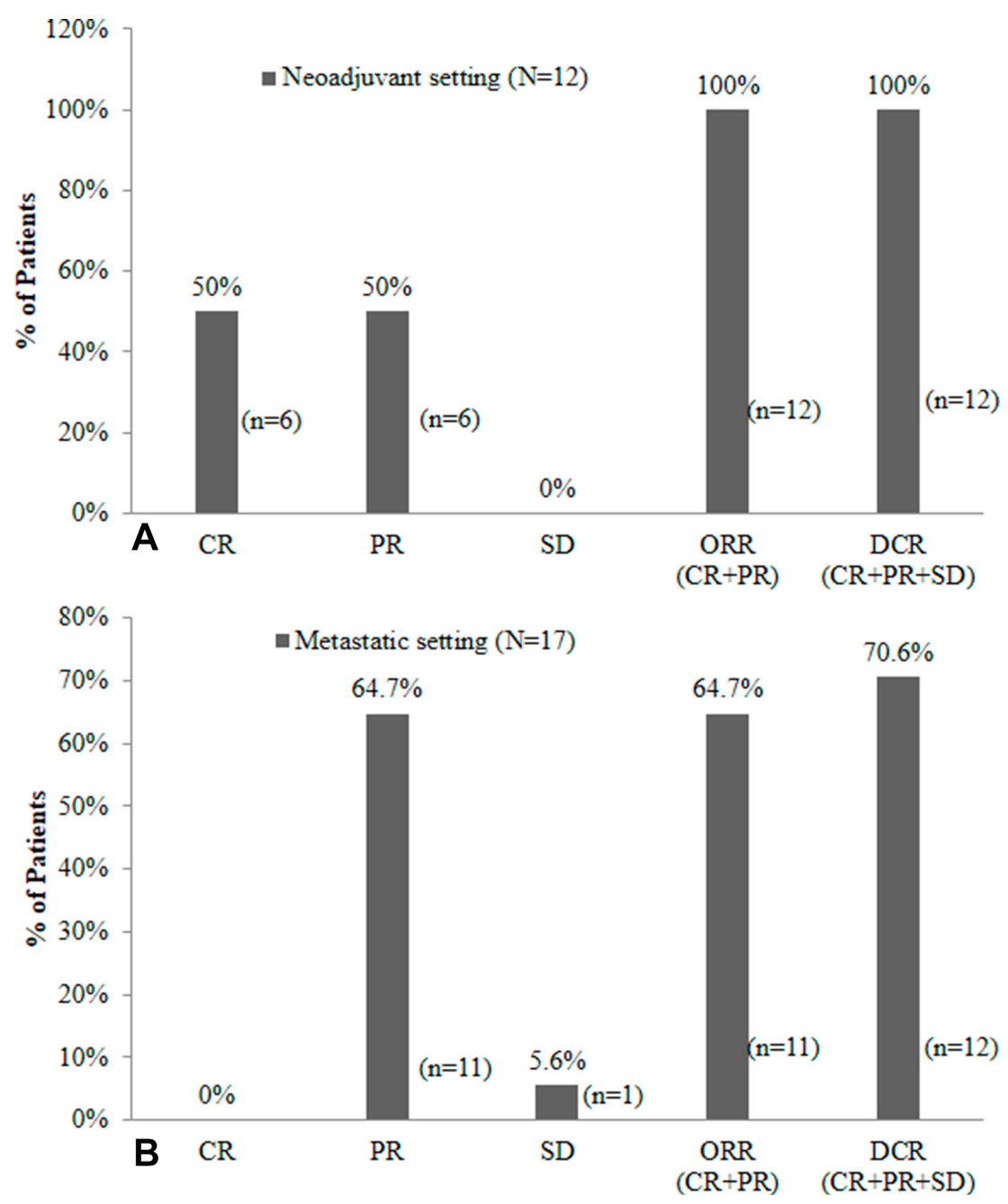

Figure I Response rate of NDLS-based chemotherapy in breast cancer in $(\mathbf{A})$ neoadjuvant setting $(n=I 2)$, and $(\mathbf{B})$ metastatic setting $(n=I 7)$.

Abbreviations: CR, complete response; DCR, disease control rate; NDLS, nanosomal docetaxel lipid suspension; ORR, overall response rate; PR, partial response; SD, stable disease.

64.7\% (PR: $64.7 \%$ [11/17]) and DCR was 70.6\% (PR: 64.7\% [11/17], SD: $5.6 \%$ [1/17]), respectively (Figure 1B).

\section{Overall Survival}

Overall, patient survival data was collected from the date of administration of the first dose of NDLS treatment till the last follow-up date (September 30, 2018) for alive patients and date of death for patients who died. Overall, 83.5\% (76/91) patients were alive at a median follow-up duration of 21.6 months (range: $2.1-49.9$ months). The proportion of patients who were alive was $91.7 \%$ (11/12) in the neoadjuvant setting [median follow-up: 21.1 months (range: 2.06-46.8 months)] (Figure 2A), 90.2\% (55/61) in the adjuvant setting [median follow-up: 21.6 months (range: 3.5-49.8 months)] (Figure 2B) and $44.4 \%(10 / 18)$ in the metastatic setting [median follow-up: 22.4 months (range: 5.1-36.9 months)]
(Figure 2C). The median OS was not reached for patients treated in neoadjuvant and adjuvant settings, whereas it was 30.4 months in metastatic setting.

\section{Safety}

The data on AEs were available for 54 patients. Of these, at least one AE was reported in $46(85.2 \%)$ patients. Grade I AEs were reported in $83.3 \%(45 / 54)$ patients, grade II in $42.6 \%(23 / 54)$, grade III in $14.8 \%(8 / 54)$ and grade IV in $5.6 \%(3 / 54)$ patients. Anemia, thrombocytopenia, lymphopenia and neutropenia were the most common hematological AEs, whereas hyperglycemia and alteration in liver function tests were the most common non-hematological AEs reported (Table 2). The AEs of interest with docetaxel such as hypersensitivity reactions, fluid retention, 

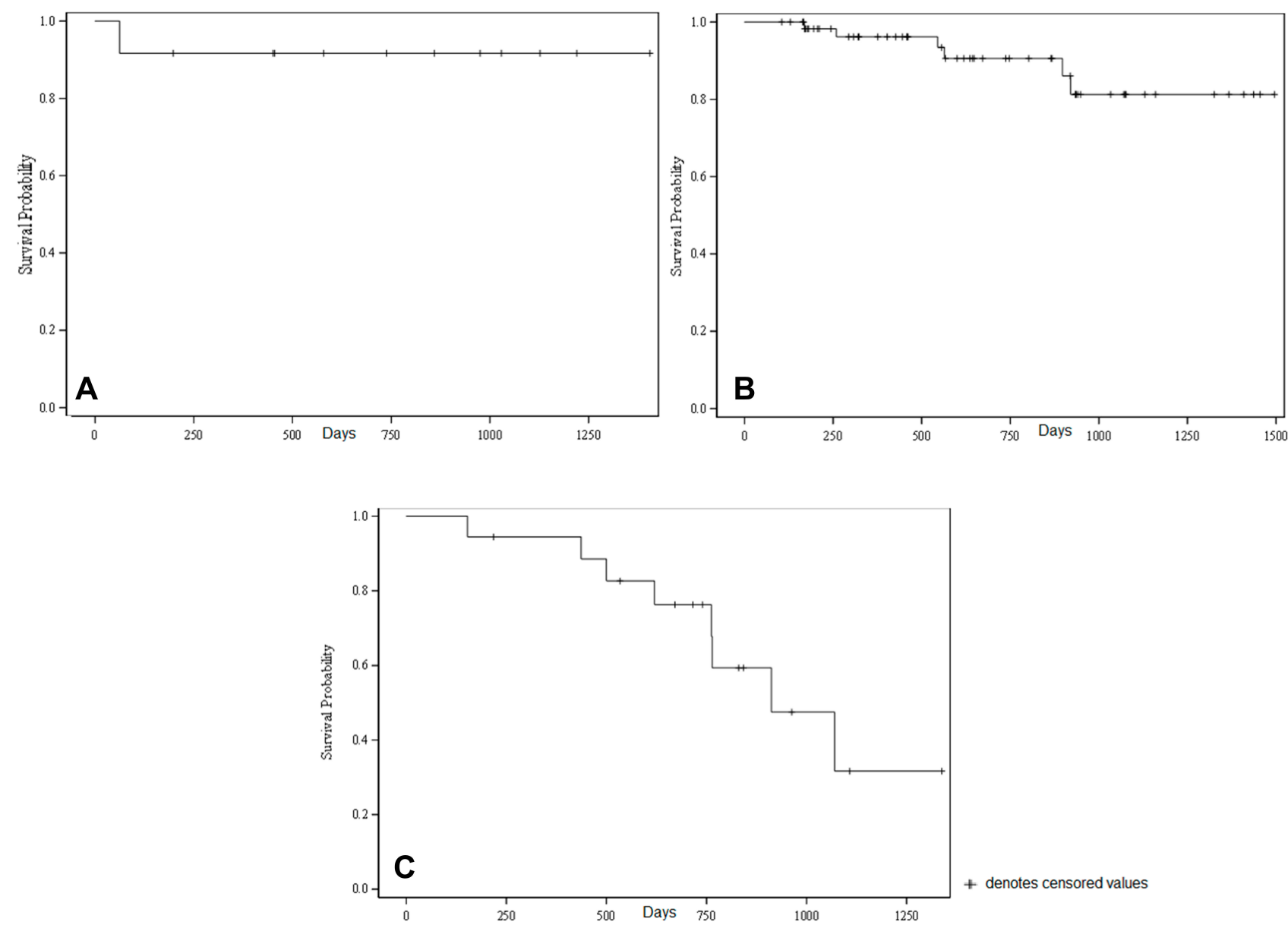

Figure 2 Kaplan-Meier estimates of overall survival in breast cancer patients: $(\mathbf{A})$ neoadjuvant $(n=\mid 2),(B)$ adjuvant $(n=6 \mid)$, and $(\mathbf{C})$ metastatic $(n=\mid 8)$ settings. The mean survival time and its standard error were underestimated because the largest observation was censored and estimation was restricted to the largest event time.

neuropathy and nail disorders, were not reported with the use of NDLS in this study.

\section{Discussion}

Docetaxel is recommended as a single agent or in combination for the treatment of breast cancer in neoadjuvant, adjuvant and metastatic settings by several guidelines. ${ }^{25,26}$ Globally several novel docetaxel formulations are being developed to overcome the toxicities related to excipients used in the conventional docetaxel formulation, among which, NDLS was approved by the Drug Controller General of India in August 2013.

NDLS was developed using the patented (worldwide [WO2008127358], Europe [2076244], Japan [5917789] and Canada [CA2666322]) "NanoAqualip" technology. ${ }^{27}$ NDLS was developed by adding docetaxel to high pressure homogenized soy phosphatidylcholine and sodium cholesteryl sulfate in sodium citrate buffer under continuous high pressure homogenization. Nanosomal lipid- based (with generally regarded as safe [GRAS] lipids by the US Food and Drug Administration) docetaxel nanoparticles $(<100 \mathrm{~nm})$ may infiltrate and get trapped in the damaged tumor vasculature and necrotic tumor tissue collagen material resulting in increased retention [enhanced permeability and retention (EPR) effect]. The efficacy and safety of NDLS has been demonstrated in breast, gastric, ovarian, cervical, penile, hormone refractory prostate and non-small cell lung cancers. ${ }^{21,28-31}$ Furthermore, a panel of oncology experts has recommended using NDLS in patients with metastatic disease, those at risk of hypersensitivity reactions, diabetics and those in whom steroids need to be avoided. ${ }^{32}$

The current study presents the findings of NDLS-based chemotherapy in breast cancer patients in neoadjuvant, adjuvant and metastatic settings. In neoadjuvant settings, achieving pathologic complete response (pCR) is associated with significantly reduced disease recurrence and improved survival in breast cancer patients. ${ }^{33}$ In our study, both ORR 
Table 2 Safety Profile of NDLS-Based Chemotherapy in Breast Cancer $(n=54)$

\begin{tabular}{|c|c|c|c|}
\hline Adverse Event & $\begin{array}{l}\text { All Grades, } \\
\text { n (\%) }\end{array}$ & $\begin{array}{l}\text { Grade III, } \\
\text { n (\%) }\end{array}$ & $\begin{array}{l}\text { Grade IV, } \\
\text { n (\%) }\end{array}$ \\
\hline $\begin{array}{l}\text { Hematological AEs } \\
\text { Anemia } \\
\text { Thrombocytopenia } \\
\text { Lymphopenia } \\
\text { Neutropenia }\end{array}$ & $\begin{array}{l}40(74.1) \\
25(46.3) \\
17(31.5) \\
5(9.3)\end{array}$ & $\begin{array}{l}2(3.7) \\
2(3.7) \\
3(5.6) \\
2(3.7)\end{array}$ & $\begin{array}{l}- \\
2(3.7) \\
- \\
2(3.7)\end{array}$ \\
\hline $\begin{array}{l}\text { Non-Hematological } \\
\text { AEs } \\
\text { Hyperglycemia } \\
\text { Alteration in liver } \\
\text { function test } \\
\text { Alopecia } \\
\text { Diarrhea } \\
\text { Hypotension } \\
\text { Mucositis } \\
\text { Rash }\end{array}$ & $\begin{array}{l}13(24.1) \\
6(11.1) \\
2(3.7) \\
\text { I (1.9) } \\
\text { I (1.9) } \\
\text { I (1.9) } \\
\text { I (1.9) }\end{array}$ & $\begin{array}{l}- \\
2(3.7) \\
- \\
- \\
- \\
- \\
-\end{array}$ & $\begin{array}{l}- \\
- \\
- \\
- \\
- \\
- \\
-\end{array}$ \\
\hline
\end{tabular}

Notes: AEs in different grades may occur in $\geq 1$ patients; hence, the cumulative number of patients in different grades may exceed the total number of patients with individual AEs.

and DCR rates were 100\% (CR: 50\%, PR: 50\%) with NDLS-based chemotherapy in the neoadjuvant setting. In this analysis, only one patient was evaluated using pathological response and achieved $\mathrm{pCR}$, and remaining patients were evaluated based on overall response criteria by RECIST 1.1. Furthermore, median OS was not reached for neoadjuvant settings; $91.7 \%$ patients were alive at last follow-up (median follow-up: 21.1 months; range: 2.06-46.8 months). NDLS was most commonly used as a $\mathrm{TCH}$ $(33.3 \%)$ regimen in the neoadjuvant setting, since $5 / 12$ (41.7\%) patients in this setting were human epidermal growth factor receptor 2 positive (HER2+). ${ }^{26}$ Previous reports on neoadjuvant treatment with taxanes, platinum agent and trastuzumab have shown ORR rates of $87.1 \%$ $(\mathrm{n}=39),{ }^{34} 98 \%(\mathrm{n}=42)^{35}$ and $100 \%(\mathrm{n}=32)^{36}$ in previous studies in patients with breast cancer treated in neoadjuvant settings. In an Indian retrospective analysis by Tiwari et al, ${ }^{36}$ TCH regimen $(n=32)$ demonstrated an ORR of $100 \%$. The higher response rate $(100 \%)$ observed in our study in neoadjuvant treatment could be attributed to the small sample size. Kolberg et $\mathrm{al}^{37}$ showed that $94.2 \%$ patients were alive at 53.6 months follow-up with a TCH regimen. ${ }^{37}$ In our study, $91.7 \%$ patients were alive at a median follow-up of 21.1 months in the neoadjuvant setting. The above evidence shows the potential of NDLS-based regimens in managing breast cancer in neoadjuvant setting.
Docetaxel in combination with anthracyclines and cyclophosphamide as concurrent (the TAC regimen) or sequentially $(\mathrm{AC} \rightarrow \mathrm{T})$ has been evaluated for adjuvant treatment in many studies. ${ }^{38}$ In our study, NDLS was most commonly used in combination as TC, TAC and TCH regimens in adjuvant setting. The US Oncology Research Trial 9735 showed an OS of $90 \%$ with adjuvant TC regimen at a median follow-up of 5.5 years in early breast cancer patients $(\mathrm{n}=506) .{ }^{39}$ The 7 -year follow-up, in this study, showed an OS rate of $87 \%$ with a TC regimen. ${ }^{40}$ The TAX316 study evaluated TAC regimen in adjuvant treatment of breast cancer and showed that $87.8 \%$ patients were alive at a median follow-up of 77 months. ${ }^{41}$ Jones et al, ${ }^{42}$ showed 98.3\% alive patients at a median follow-up of 36.1 months who had received an adjuvant TCH regimen. In our study, at a median follow-up of 21.6 months (range: 3.5-49.8 months), the median OS was not reached for adjuvant setting and $90.2 \%(55 / 61)$ patients were still alive.

Docetaxel has been established as an effective treatment option in the treatment of MBC after failure of prior chemotherapy. ${ }^{43}$ Conventional docetaxel has reported an ORR of $30-47 \%$ in MBC at various dose levels. ${ }^{44,45}$ The efficacy and safety of NDLS was compared with conventional docetaxel in the management of MBC by Ahmad et al. NDLS monotherapy demonstrated an ORR of 35.5\% $(\mathrm{n}=49)$ vs $26.3 \%(\mathrm{n}=23)$ with conventional docetaxel at $75 \mathrm{mg} / \mathrm{m}^{2}$ in the treatment of 72 locally advanced or MBC patients. The safety was comparable between NDLS and conventional docetaxel, though patients in the NDLS group were not premedicated with corticosteroids. In our study, NDLS plus carboplatin and TCH were the most common NDLS-based regimens used in metastatic settings. In a study by Mavroudis et $\mathrm{al}^{46}{ }^{46}$ docetaxel plus carboplatin showed an ORR of $61 \%$ in MBC patients $(\mathrm{n}=36)$. The NCCTG 9932 trial showed an ORR of 58\% with docetaxel plus carboplatin in 35 patients. ${ }^{47}$ The Phase III BCIRG 007 study by Valero et $\mathrm{al}^{48}$ demonstrated an ORR of $72 \%$ and median OS of 37.4 months for TCH regimen in HER2+ MBC patients $(\mathrm{n}=132) .{ }^{48} \mathrm{TCH}$ demonstrated an ORR of $79 \%(\mathrm{n}=62)$ in the BCIRG 101 study and $58 \%(\mathrm{n}=59)$ in the UCLA-ORN study for the treatment of MBC. ${ }^{49}$ In our analysis, NDLS-based regimens demonstrated an ORR and DCR of $64.7 \%$ and $70.6 \%$, respectively. At a median follow-up of 22.4 months (range: 5.1-36.9 months), the median OS was 30.4 months and $44.4 \%$ patients were still alive.

Overall, NDLS-based regimens were found to be well tolerated in breast cancer patients. GCSF was used in most 
of the patients and the safety profile of NDLS in this study is consistent with previous literature. ${ }^{20,22,50}$ In the TAX313 study, fluid retention (38\%), thrombocytopenia (11\%), neutropenia (94\%), febrile neutropenia $(7 \%)$, treatmentrelated grade III/IV infection (3\%) and anemia (94\%) were the most common AEs with conventional docetaxel. In our study, severe grade IV neutropenia and thrombocytopenia were reported in $2(3.70 \%)$ patients, which resolved with supportive therapy. The most commonly reported grade III AEs were lymphopenia (5.6\%), anemia, thrombocytopenia and neutropenia (3.7\% each), and grade IV AEs were neutropenia and thrombocytopenia $(3.7 \%$ each). The AEs of interest with conventional docetaxel formulation such as hypersensitivity reactions, fluid retention, neuropathy and nail disorders were not observed with NDLS in our study. Hyperglycemia was the most common non-hematological $\mathrm{AE}$ which could be attributed to the fact that $23.1 \%$ of the patients in this study had diabetes at baseline and the majority of the patients received corticosteroids as premedication. The major limitation of this study is its retrospective nature and data availability with respect to survival and safety. The progression-free survival (PFS) could not be captured in this study since being a real-world study, the data on progression and serial scans were not available for most of the patients at most of the follow-up timepoints. This is one of the major limitations of this study.

\section{Conclusion}

The novel nanosomal docetaxel lipid suspension (NDLS)based chemotherapy was effective and well tolerated in managing breast cancer in all settings. Furthermore, NDLS is being evaluated prospectively in patients with triplenegative breast cancer (ClinicalTrials.gov identifier: NCT03671044)

\section{Acknowledgments}

The authors thank Mr Shreekant Sharma, MPharm, ISMPP $\mathrm{CMPP}^{\mathrm{TM}}$ (Lambda Therapeutic Research Ltd., Ahmedabad, Gujarat, India) for providing writing assistance and Dr Venugopal Madhusudhana, MBBS, EPBM, ISMPP CMPP $^{\mathrm{TM}}$ (Lambda Therapeutic Research Ltd., Ahmedabad, Gujarat, India) for additional editorial assistance for the development of this manuscript. The authors also thank the clinical data management and biostatistics department of Lambda Therapeutic Research Ltd. for their contribution in the preparation of the statistical analysis report in this retrospective data collation and analysis.

\section{Author Contributions}

SS, RP, GB, SKDM performed the research, were involved in the acquisition of data, critically revised the manuscript for important intellectual content, and approved the final manuscript. NJ, DB, MAK and IA designed the study, were involved in the data interpretation, critically revised the manuscript for important intellectual content, and approved the final manuscript. All authors made substantial contributions to this study and agree to be accountable for all aspects of the work.

\section{Funding}

This study was funded by an unrestricted research grant by Intas Pharmaceuticals Ltd., Ahmedabad, Gujarat, India.

\section{Disclosure}

Drs Mujtaba A Khan, Deepak Bunger and Nisarg Joshi are employees of Intas Pharmaceuticals Ltd., India, and the product being mentioned is manufactured and marketed by Intas Ltd. Dr Imran Ahmad is an employee of Jina Pharmaceuticals Inc., USA. The authors report no other conflicts of interest in this work.

\section{References}

1. Ghoncheh M, Pournamdar Z, Salehiniya H. Incidence and mortality and epidemiology of breast cancer in the world. Asian Pac $J$ Cancer Prev. 2016;17(S3):43-46. doi:10.7314/APJCP.2016.17. $\mathrm{S} 3.43$

2. Bray F, Ferlay J, Soerjomataram I, et al. Global cancer statistics 2018: GLOBOCAN estimates of incidence and mortality worldwide for 36 cancers in 185 countries. CA Cancer J Clin. 2018;68(6):394-424. doi: $10.3322 /$ caac. 21492

3. National Institute for Cancer Prevention and Research. Globocan 2018: India Factsheet. Available from: http://cancerindia.org.in/globo can-2018-india-factsheet/. Accessed April 21, 2020.

4. Crown J, O'Leary M, Ooi WS. Docetaxel and paclitaxel in the treatment of breast cancer: a review of clinical experience. Oncologist. 2004;9Suppl 2(S2):24-32. doi:10.1634/theoncologist.9-suppl_2-24

5. Taxotere $^{\circledR}$ Prescribing Information. sanofi-aventis U.S. LLC, NJ 08807. Revised May, 2010.

6. Amat S, Bougnoux P, Penault-Llorca F, et al. Neoadjuvant docetaxel for operable breast cancer induces a high pathological response and breast-conservation rate. $B r \quad J$ Cancer. 2003;88(9):1339-1345. doi:10.1038/sj.bjc.6600916

7. von Minckwitz G, Untch M, Blohmer JU, et al. Definition and impact of pathologic complete response on prognosis after neoadjuvant chemotherapy in various intrinsic breast cancer subtypes. J Clin Oncol. 2012;30(15):1796-1804. doi:10.1200/JCO.2011.38.8595

8. Weiszhár Z, Czúcz J, Révész C, et al. Complement activation by polyethoxylated pharmaceutical surfactants: cremophor-EL, Tween-80 and Tween-20. Eur J Pharm Sci. 2012;45(4):492-498. doi:10.1016/j.ejps.2011.09.016

9. Pritchett W, Kinsley K. Benefits and risks of fosaprepitant in patients receiving emetogenic regimens. Clin $J$ Oncol Nurs. 2016;20 (5):555-556. doi:10.1188/16.CJON.555-556 
10. Fumoleau $\mathrm{P}$, Tubiana-Hulin $\mathrm{M}$, Soulie $\mathrm{P}$, et al. A dose finding and pharmacokinetic (PK) Phase I study of a new formulation of docetaxel (D) in advanced solid tumors. [abstract]. Ann Oncol. 1998;9 (Suppl. 2):101.

11. Ten Tije AJ, Verweij J, Loos WJ, Sparreboom A. Pharmacological effects of formulation vehicles: implications for cancer chemotherapy. Clin Pharmacokinet. 2003;42(7):665-685. doi:10.2165/00003088200342070-00005

12. Coors EA, Seybold H, Merk HF, Mahler V. Polysorbate 80 in medical products and nonimmunologic anaphylactoid reactions. Ann Allergy Asthma Immunol. 2005;95(6):593-599. doi:10.1016/S1081-1206(10) 61024-1

13. Schwartzberg LS, Navari RM. Safety of polysorbate 80 in the oncology setting. Adv Ther. 2018;35(6):754-767. doi:10.1007/s12325-0180707-z

14. FDA Drug Safety Communication (2014, June 20). FDA warns that cancer drug docetaxel may cause symptoms of alcohol intoxication after treatment. Available From: https://www.fda.gov/Drugs/ DrugSafety/ucm401752.htm. Accessed April 21, 2020.

15. Mirza A, Mithal N. Alcohol intoxication with the new formulation of docetaxel. Clin Oncol ( $R$ Coll Radiol). 2011;23(8):560-561. doi:10.1016/j.clon.2011.04.010

16. Piccart MJ, Klijn J, Paridaens R, et al. Corticosteroids significantly delay the onset of docetaxel-induced fluid retention: final results of a randomized study of the European organization for research and treatment of cancer investigational drug branch for breast cancer. J Clin Oncol. 1997;15(9):3149-3155. doi:10.1200/JCO.1997.15.9.3149

17. Jung JW, Choi YH, Park CM, et al. Outcomes of corticosteroid prophylaxis for hypersensitivity reactions to low osmolar contrast media in high-risk patients. Ann Allergy Asthma Immunol. 2016;117 (3):304-309.e301. doi:10.1016/j.anai.2016.07.010

18. Alken S, Kelly CM. Benefit risk assessment and update on the use of docetaxel in the management of breast cancer. Cancer Manag Res. 2013;5:357-365. doi:10.2147/CMAR.S49321

19. Weiss RB, Donehower RC, Wiernik PH, et al. Hypersensitivity reactions from taxol. J Clin Oncol. 1990;8(7):1263-1268. doi:10.1200/ JCO.1990.8.7.1263

20. Ahmad A, Sheikh S, Taran R, et al. Therapeutic efficacy of a novel nanosomal docetaxel lipid suspension compared with taxotere in locally advanced or metastatic breast cancer patients. Clin Breast Cancer. 2014;14(3):177-181. doi:10.1016/j.clbc.2013.09.011

21. Ashraf M, Sajjad R, Khan M, et al. 156P Efficacy and safety of a novel nanosomal docetaxel lipid suspension (NDLS) as an anti cancer agent-a retrospective study. Ann Oncol. 2016;27(suppl_9). doi:10.1093/annonc/mdw579.008.

22. Murali A, Gupta S, Pendharkar D. Efficacy and tolerability of nanoparticle docetaxel lipid suspension. J Clin Oncol. 2018;36(15_suppl): e14542-e14542. doi:10.1200/JCO.2018.36.15_suppl.e14542

23. Eisenhauer EA, Therasse P, Bogaerts J, et al. New response evaluation criteria in solid tumours: revised RECIST guideline (version 1.1). Eur J Cancer. 2009;45(2):228-247. doi:10.1016/j.ejca.2008. 10.026

24. National Cancer Institute. Common Terminology Criteria for Adverse Events (CTCAE) v5.0. Available from: https://ctep.cancer.gov/proto coldevelopment/electronic_applications/docs/CTCAE_v5_Quick_ Reference_5x7.pdf. Accessed April 21, 2020.

25. National Comprehensive Cancer Network (NCCN). Breast Cancer Guidelines 2019.

26. Cardoso F, Senkus E, Costa A, et al. 4th ESO-ESMO international consensus guidelines for advanced breast cancer (ABC 4) †. Ann Oncol. 2018;29(8):1634-1657. doi:10.1093/annonc/mdy 192

27. Ahmad A, Sheikh S, Ali SM, et al. Development of aqueous based formulation of docetaxel: safety and pharmacokinetics in patients with advanced solid tumors. J Nanomed Nanotechnol. 2015;6(3):1.
28. Naik R, Khan MA. Doceaqualip in a patient with prostate cancer who had an allergic reaction to conventional docetaxel: a case report. Mol Clin Oncol. 2017;6(3):341-343. doi:10.3892/mco.2017.1147

29. Prasanna R, Bunger D, Khan MA. Efficacy and safety of DoceAqualip in a patient with locally advanced cervical cancer: a case report. Mol Clin Oncol. 2018;8(2):296-299. doi:10.3892/ mco.2017.1519

30. Vyas V, Joshi N, Khan M. Novel docetaxel formulation (NDLS) in low cardiac reserve ovarian cancer. Open Access J Cancer Oncol. 2018;2(2):000122.

31. Gupta S, Pawar SS, Bunger D. Successful downstaging of locally recurrent penile squamous cell carcinoma with neoadjuvant nanosomal docetaxel lipid suspension (NDLS) based regimen followed by curative surgery. BMJ Case Rep. 2017;2017.

32. Rajappa S, Joshi A, Doval DC, et al. Novel formulations of docetaxel, paclitaxel and doxorubicin in the management of metastatic breast cancer. Oncol Lett. 2018;16(3):3757-3769. doi:10.3892/ ol.2018.9057

33. Spring L, Greenup R, Reynolds K, Smith BL, Moy B, Bardia A. Pathological complete response after neoadjuvant chemotherapy predicts improved survival in all major subtypes of breast cancer: systematic review and meta-analyses of over 18,000 patients. Presented at the 2016 AACR Ann Meeting. 2016. Abstract 1439.

34. Li S, Wei W, Jiang Y, et al. Comparison of the efficacy and survival analysis of neoadjuvant chemotherapy for Her-2-positive breast cancer. Drug Des Devel Ther. 2018;12:3085-3093. doi:10.2147/ DDDT.S171534

35. Zuradelli M, Gullo G, Walshe J, et al. 446 docetaxel, carboplatin and trastuzumab (TCH) as Neoadjuvant (neoadj) therapy in patients (pts) with HER2-positive (HER2+) Operable Breast Cancer (BrCa). Eur J Cancer. 2012;48:S177. doi:10.1016/S0959-8049(12)70511-7

36. Tiwari A, Gogia A, Deo S, et al. Retrospective study of efficacy and safety of neoadjuvant docetaxel, carboplatin, and trastuzumab in HER2-positive locally advanced and oligometastatic breast cancer: an Indian experience. Indian $J$ Cancer. 2017;54(1):343-346. doi:10.4103/ijc.IJC_152_17

37. Kolberg H-C, Akpolat-Basci L, Stephanou M, Hannig C, Liedtke C. Neoadjuvant chemotherapy with docetaxel, carboplatin, and weekly trastuzumab (TCH) activity in HER2-positive early breast cancer: results after a median follow-up of 4.5 years. J Clin Oncol. 2015;33 (28_suppl):140. doi:10.1200/jco.2015.33.28_suppl.140

38. Martin M. Docetaxel, doxorubicin and cyclophosphamide (the TAC regimen): an effective adjuvant treatment for operable breast cancer. Womens Health. 2006;2(4):527-537. doi:10.2217/174550 57.2.4.527

39. Jones SE, Savin MA, Holmes FA, et al. Phase III trial comparing doxorubicin plus cyclophosphamide with docetaxel plus cyclophosphamide as adjuvant therapy for operable breast cancer. $J$ Clin Oncol. 2006;24(34):5381-5387. doi:10.1200/JCO.2006.06.5391

40. Jones S, Holmes FA, O'Shaughnessy J, et al. Docetaxel with cyclophosphamide is associated with an overall survival benefit compared with doxorubicin and cyclophosphamide: 7-year follow-up of us oncology research trial 9735. J Clin Oncol. 2009;27(8):1177-1183. doi: $10.1200 /$ JCO.2008.18.4028

41. Martin M, Pienkowski T, Mackey J, et al. Adjuvant docetaxel for node-positive breast cancer. $N$ Engl J Med. 2005;352(22):2302-2313. doi:10.1056/NEJMoa043681

42. Jones SE, Collea R, Paul D, et al. Adjuvant docetaxel and cyclophosphamide plus trastuzumab in patients with HER2-amplified early stage breast cancer: a single-group, open-label, Phase 2 study. Lancet Oncol. 2013;14(11):1121-1128. doi:10.1016/S1470-2045(13)70384-X

43. Lyseng-Williamson KA, Fenton C. Docetaxel: a review of its use in metastatic breast cancer. Drugs. 2005;65(17):2513-2531. doi:10.21 65/00003495-200565170-00007 
44. Nabholtz JM, Senn HJ, Bezwoda WR, et al. Prospective randomized trial of docetaxel versus mitomycin plus vinblastine in patients with metastatic breast cancer progressing despite previous anthracycline-containing chemotherapy. 304 Study Group. J Clin Oncol. 1999;17(5):1413-1424. doi:10.1200/JCO.1999.17.5.1413

45. Chan S. Docetaxel vs doxorubicin in metastatic breast cancer resistant to alkylating chemotherapy. Oncology (Williston Park). 1997;11 (8 Suppl 8):19-24.

46. Mavroudis D, Alexopoulos A, Malamos N, et al. Salvage treatment of metastatic breast cancer with docetaxel and carboplatin. A multicenter Phase II trial. Oncology. 2003;64(3):207-212. doi:10. 1159/000069306

47. Perez EA, Suman VJ, Fitch TR, et al. A phase II trial of docetaxel and carboplatin as first-line chemotherapy for metastatic breast cancer: NCCTG study N9932. Oncology. 2005;69(2):117-121. doi:10.11 $59 / 000087813$
48. Valero V, Forbes J, Pegram MD, et al. Multicenter phase III randomized trial comparing docetaxel and trastuzumab with docetaxel, carboplatin, and trastuzumab as first-line chemotherapy for patients with HER2-gene-amplified metastatic breast cancer (BCIRG 007 study): two highly active therapeutic regimens. J Clin Oncol. 2011;29(2):149-156. doi:10.1200/JCO.2010.28. 6450

49. Riva A, Reese D, Toppmeyer D, et al. Results of Two open-label, multicenter phase ii studies of docetaxel, platinum salts, and trastuzumab in HER2-positive advanced breast cancer. JNCI. 2004;96 (10):759-769. doi:10.1093/jnci/djh133

50. Ashraf QM, Sajad QR, Khan MA, et al. Efficacy and safety of a novel nanosomal docetaxel lipid suspension as an anticancer agent - a retrospective study. J Cancer Oncol. 2018;2(4):000132.

\section{Publish your work in this journal}

Breast Cancer - Targets and Therapy is an international, peer-reviewed open access journal focusing on breast cancer research, identification of therapeutic targets and the optimal use of preventative and integrated treatment interventions to achieve improved outcomes, enhanced survival and quality of life for the cancer patient.
The manuscript management system is completely online and includes a very quick and fair peer-review system, which is all easy to use. Visit http://www.dovepress.com/testimonials.php to read real quotes from published authors. 